think of writing a book on psychology in general. This collection of papers, edited by the director of the Edinburgh MRC Speech and Communication Research Unit, and Dr J. C. Marshall of his staff, is a clear verification of that prediction.

'These twenty-five important papers on the psychology of language and related linguistic studies are grouped into five sections. Eighteen papers have been published since 1964, and all but one--Shannon's fundamental monograph of 1948 - since 1956. British work is not ill represented, although it has perhaps been more influential in the area of brain function than the single paper by Brain suggests.

These dates are significant. The Bell Telephone Laboratories had been early in the field with Harvey Fletcher's Speech and Hearing (1929). But the development since the war of communication theory, and the work of the theoretical linguists like Chomsky and his colleagues at the Massachusetts Institute of Technology, have stimulated experimental research, as Oldfield and Marshall point out, "not only into normal language function but into the problems of language development in the child, and into the pathological manifestations found in mental and nervous disease. . . As mattors stand at present ... it is fair to say that by far the largest part of the psychology of language is dominated by these conceptions".

The rapid growth of "psycholinguistics" is not a mere fashion. It is one of the clearest examples of the ways in which the direction of scientific, especially psychological, enquiry is responsive to the pressures of its immediate social environment. In so far as society not only depends upon but virtually is communication, the need to understand the processes of communication-that is, of speech and language-becomes paramount. It is also another evidence, as it is in part a cause, of current dissatisfaction with performance-models based on Watsonian-Hullian learning theory. It is an important demonstration of our recognition that experimentation with animals, although convenient, is of little help in interpreting the speciesspecific aspects of human behaviour.

The field eultivated in the name of psycholinguistics is enormously wide, and the editors have had to omit much. Virtually no mention is made of animal communication, or of the study of speech and language in their social setting, although the latter is certainly implicit in the developmental studies. But the papers are representative of many of the main lines of current experimental enquiry. The reader will have to face the fact that in some of its aspects contemporary psycholinguistic theory has reached a considerable level of sophistication, so that the book is certainly not for him who runs to read. But if the student (at graduate level or otherwise) of this turbulent field will keep his seat-belt fastened, he will get a valuable demonstration of how psychology, like the other biological sciences, must come to grips with the problems of organized complexity.

George Seth

\section{INTRODUCTIONS TO GENETICS}

Man and Heredity

By G. W. Roderick. Pp. ix + 240. (Macmillan: London; St Martin's Prcss: New York, 1968.) 37s. 6d.

Elements of Medical Genetics

By Alan E. H. Emery. Pp. ix +247. (Livingstone: Edinburgh and London, 1968.) 35s.

IT is interesting for a reviewer to be able to compare and contrast two books which have been published at the same time, cover similar ground, and are of comparable length and price. Professor Emery and Mr Roderick have both taught human geneties and these two introductory books are the fruits of their experience. A difference in approach is apparent to the reader from the start. Emery writes essentially for medical students and clinicians (although the book is suitable for other scientists). Roderick aims at a different spectrum of readers: laymen and interested biologists up to and including medical students.

Both books have similar ranges, starting with sections on history and cytology and passing through what is known of human inheritance to consideration of the genetic effects of radiation and elementary genetic counselling. Perhaps the most obvious difference is that Emery has collected data on population genetics and pharmacogenetics into discrete chapters, to the advantage of both topics. When reading the two books in parallel, however, one is immediately conscious of the difference between an author who is steeped in all aspects of the subject (Emery) and one who is working at second hand, albeit very competently (Roderick). Thus it is not difficult to find in Roderick's book statements which are only half truths and could be misleading. The following examples come from a single chapter (2). Nucleoli-"each nucleus contains a characteristic number of these structures; this number for man is four". Later it is stated that " $X X$ determinos male sex in certain birds and moths", but "in certain fowls males are $X$ and females $X X$ ". Further on, "in man it has been found that certain parts of the $X$ and $Y$ chromosomes are genetically identical"- - something which as Emery points out is certainly no more than an interesting possibility. A diagram of a generalized (? plant) cell could have been drawn fifty years ago (Emery in a comparable diagram takes notice of the invention of the electron microscope). Examples of this kind are to be found elsewhere in Roderick's book, but to be fair to him he writes much better on subjects which interest him more, such as the mechanisms of gene action and the actual process of inheritance in man; here his slightly journalistic style, combined with excellent diagrams and photographs, makes his book attractive to the general reader.

But Roderick's book inevitably suffers in comparison with Emery's because the latter is so accurate and well balanced. He resists the temptation to dilate on such popular topics as the DNA saga or the haemophiliac descendants of Queen Victoria (not that either DNA or haemophilia is ignored; they are dealt with in the lucid but economical style which characterizes the whole book). He can, of course, assume that his readers are familiar with the biochemistry of DNA and have heard of haemophilia. A layman, coming to these topics for the first time, might find the account too terse and dry and assuming too much background knowledge.

Both books have good references; Emery's go closer to the source and would be more valuable to the specialist, while Roderick's are more suitable for the general reader. Emery's book can be criticized for its illustrations, which are all black-and-white and often too small. Where chromosomes and patients with chromosome abnormalities are concerned, there is something first-hand in a photograph which no drawing can convey, and here Roderick's book is better.

Emery's book can be recommended unreservedly to medical students, clinicians and professional scientists for its accuracy, up-to-dateness and balance. One inevitably compares it to other well known short works on human genetics, such as those of J. A. Fraser Roberts, C. A. Clarke, C. O. Carter, E. B. Ford and L. S. Penrose. In many ways it is a better introduction than any of these because of its breadth and balanced coverage; yet just because of these qualities it has an impersonality not found in some of these other works where the author's personal interests obtrude more strongly. Despite the fact that the book covers no subject in depth it may be too technical for the layman; the latter may prefer Mr Roderick's more popularly written (but less authoritative) book.

E. H. R. FORD 